\title{
Dimensões da competência em informação sob a perspectiva de Zarifian
}

\author{
Ana Cristina de Souza ${ }^{I}$ \\ https://orcid.org/0000-0002-6891-7291 \\ Eliana Maria dos Santos Bahia ${ }^{I I}$ \\ https://orcid.org/0000-0003-4037-3189 \\ Elizete Vieira Vitorino ${ }^{I I I}$ \\ https://orcid.org/0000-0003-2462-6553 \\ I Universidade Federal de Santa Catarina, SC, Brasil. \\ Mestranda em Ciência da Informação.

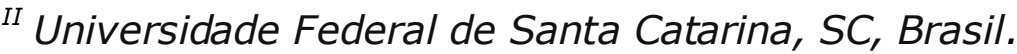 \\ Docente no Programa de Pós-graduação em Ciência da Informação.

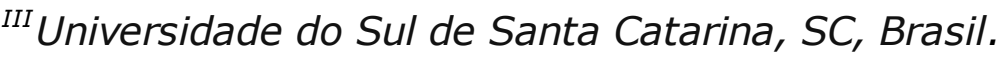 \\ Docente no Programa de Pós-graduação em Ciência da Informação
}

http://dx.doi.org/10.1590/1981-5344/3903

O propósito deste artigo é analisar a obra "Objetivo Competência: por uma nova lógica" de Phillipe Zarifian (2001), utilizando-a como fio condutor para reflexões acerca das dimensões da competência em informação. $A$ escolha da obra deve-se ao fato da mesma, mesmo que em contexto da área da administração, apresentar conexões com as quatro dimensões anunciadas por Vitorino e Piantola $(2011$; 2019) e apreciadas no estudo de Rios (2006; 2010): técnica, estética, ética e política. Esta perspectiva adotada em meio ao processo de releitura e análise do conteúdo da obra, ainda que no contexto da década de 90, mostra-se atual às reflexões sobre a competência em informação. Foram abordados aspectos históricos e conceituais da competência a partir das concepções de Zarifian (2001) e destacadas as 
características das quatro dimensões que contemplam as faces da competência em informação, que, em equilíbrio, permeiam o desenvolvimento humano, tanto na perspectiva individual, quanto no âmbito da coletividade e das relações sociais. Conclui-se que a obra apresenta aproximações à competência em informação nas dimensões técnica, estética, ética e política com ênfase na transição da lógica do trabalho à lógica da competência.

Palavras-chave: Competência; Dimensões da Competência; Competência em Informação.

\section{Dimensions of information literacy under the perspective of Zarifian}

The purpose of this article is to analyze the work "Objetivo Competência: por uma nova logic" by Phillipe Zarifian (2001), using it as a guiding thread for reflections on the dimensions of information competence. The choice of the work is due to the fact that, even in the context of the administration area, it presents connections with the four dimensions announced by Vitorino and Piantola (2011; 2019) and appreciated in the study by Rios (2006; 2010): technical, aesthetics, ethics and politics. This perspective adopted in the middle of the process of rereading and analyzing the content of the work, even in the context of the 90s, shows itself current to the reflections on the competence in information. For this, historical and conceptual aspects of competence were approached from the conceptions of Zarifian (2001) and highlighted the characteristics of the four dimensions that contemplate the faces of information competence, which, in balance, permeate human development, both in the individual perspective, and in the scope of collectivity and social relations. It is concluded that the work presents approaches to competence in the technical, aesthetic, ethical and political dimensions with an emphasis on the transition from the logic of work to the logic of competence. 
Keywords: Competence; Dimensions of competence; Information Literacy.

Recebido em 13.03.2019 Aceito em 13.05.2020

\section{Introdução}

As transformações no mundo do trabalho com a passagem dos métodos de produção artesanal para a modernização dos aparelhos de produção e intensificação dos modelos taylorista e fordista na realização das tarefas, remontam a transição da noção do conceito de qualificação vinculada ao posto de trabalho para a noção de competência. (TOMASI, 2004).

Por consequência destas mutações, o conceito de qualificação para a produção em meio ao processo de formação profissional passou a ser redefinido e questionado ao longo da década de 1970, conforme aponta Miranda (2004). Passa-se a falar, na lógica da competência.

Em meio a esta atmosfera de construção e evolução, a noção de competência vem sendo empregada sob os diversos enfoques e aspectos, desde o surgimento dos seus primeiros questionamentos e reflexões. 0 conceito que desponta na literatura francesa nos anos 90 com os desdobramentos da obra "Objetivo Competência" de PhillipeZarifian (2001), procura refletir sobre o posto de trabalho para além do conceito de qualificação, buscando a competência efetiva do indivíduo em relação às demandas impostas pela sociedade pós-capitalista (TOMASI, 2004).

A competência como a capacidade de mobilizar conhecimentos junto aos postos de trabalho reafirma o conceito estreito da qualificação e voltase ao desenvolvimento humano, abrangendo-se ao uso social, intelectual e científico. Destarte, à medida que a competência se insere no campo educacional, amplia-se o conceito de cidadania e competência no âmbito social (RIOS, 2006).

No contexto do desenvolvimento humano e processo de abstração de conhecimentos, aponta-se para a competência em informação. Esta, entre outras conotações, designada por Paul Zurkowski (1974) com estudos e movimentos de proporção global foi apreciada na década de 70 a partir do termo informationliteracy (HATSCHBACH, 2002).

Nesta perspectiva, o aprendizado contínuo torna-se fator de exigência no mercado competitivo em constante mutação, em que a informação configura-se como insumo precedente para o desenvolvimento e ampliação de conhecimentos, ou seja, para a construção de uma competência reflexiva no âmbito individual e coletivo. (RIOS, 2006; FREIRE, 2007; VITORINO; PIANTOLA, 2011; 2019).

Rios (2006) aponta para a compreensão e ensino no mundo contemporâneo em meio à articulação entre filosofia e didática para a 
construção contínua de competência. A reflexão entre os saberes em relação à formação e prática profissional denotam a conexão estreita entre as dimensões técnica, estética, ética e política apreciadas no estudo.

Associa-se, que as mudanças do mundo do trabalho intensificam o aprimoramento dos profissionais frente às demandas econômicas, políticas e socioculturais, que resultam em novas formas de consumo, organização, produção e técnicas mercadológicas (RIFKIN, 2012). Panorama este que nos faz refletir acerca de um ensino que possibilite prover a informação nas pessoas e colaborar com a construção do conhecimento, implicando na importância de desenvolver a competência em informação em sociedade emergente.

Segundo Vitorino e Piantola (2009) na última década a proliferação de pesquisas inerentes à competência em informação direciona iniciativas ou modelos em áreas que ultrapassam o campo usual, como ciências médicas, direito, política e informática. Os primeiros resultados apontam para a perspectiva educacional com bases filosóficas acerca das dimensões: técnica, estética, ética e política como as faces da competência no campo da educação, servindo tanto à competência quanto à informação (VITORINO; PIANTOLA, 2009). A competência em informação em suas dimensões técnica, estética, ética e política, apreciadas nos estudos de Vitorino $(2007$; 2009; 2016) e, Vitorino e Piantola (2009; 2011; 2019) e inicialmente apresentadas por Rios (2006) na perspectiva do campo educacional, amplia a compreensão de cenários em constantes mudanças quanto às necessidades informacionais da sociedade (VITORINO, 2009). O que sugere a necessidade do aprofundamento de sua caracterização sob o foco dessas quatro dimensões.

Nesta perspectiva, e sabendo da atualidade das ideias Philippe Zarifian quanto às dimensões da competência apresentadas na obra "Objetivo Competência: por uma nova lógica", objetivamos, neste estudo, analisar o discurso proferido pelo autor, ainda que na década de 90 , com o propósito de identificar as quatro dimensões: técnica, estética, ética e política no contexto da época e adequadas ao contexto recente. Argumenta-se que a releitura da obra sob este olhar, pode trazer novos significados à competência em informação, principalmente no que refere à competência em informação no ambiente de trabalho, tema ainda pouco explorado no cenário brasileiro.

No trabalho empreendido, são identificadas e analisadas as dimensões da competência conduzidas dos estudos de Rios (1993a; 1995a; 1997; 1998; 2004; 2006; 2010) e transferidas para o campo da Ciência da Informação nos estudos acerca da competência em informação por Vitorino (2007; 2009; 2016) e, Vitorino e Piantola (2009; 2011), na 
obra de Zarifian (2001) apontando para novos enfoques no contexto dos estudos e novos olhares acerca da temática.

O estudo, mediante processo de releitura e análise do conteúdo da obra, denota novas conotações e interpretações acerca dos estudos de competência em informação a partir de novas visões sobre o livro "Objetivo Competência: por uma nova lógica" para o campo da Ciência da Informação. A compreensão de que as quatro dimensões apreciadas nos estudos de Terezinha Azerêdo Rios (2006; 2010) eram existentes na década de 90 , quando da transição do conceito de qualificação para o posto de trabalho para o início da noção de competência como fator de aprendizado e desenvolvimento humano e profissional, emerge da compilação e reflexão da obra, sugerindo a ampliação dos estudos sobre estas dimensões como pilares para o desenvolvimento da competência em informação.

\section{Metodologia da pesquisa}

Para a construção do conhecimento científico, cabe o planejamento do caminho da pesquisa e sua apresentação ao leitor, de modo a alcançar determinado propósito (BARROS; LEHFELD, 2007).

A caracterização desta pesquisa classifica-se quanto à natureza, em pesquisa básica, pois, como acentua Kerlinger (2013) objetiva a geração de conhecimentos e compreensão de fenômenos, destinando-se a expandir a base de conhecimento científico, tendo em vista o desenvolvimento e ampliação do escopo dos estudos sobre as dimensões da competência em informação.

Quanto ao objetivo, caracteriza-se como abordagem exploratória e descritiva, tratados pelo estudo das dimensões da competência em informação sob o foco de Philippe Zarifian (2001) e registro dos resultados por intermédio da descrição do tema.

Para Almeida (2011, p. 31) à pesquisa exploratória trata-se de pesquisa metodológica que explora a realidade em busca de conhecimentos. Salienta Almeida (2011) que a pesquisa descritiva possui o escopo de descrever o objeto estudado, seus atributos e dificuldades relacionadas.

A exploração e desenvolvimento da pesquisa foram realizados mediante busca direcionada à bibliografia, caracterizando-se como uma pesquisa de característica bibliográfica (RAMPAZZO, 2013) sobre temática do estudo, tendo em vista fundamentação teórica acerca do conceito e bases teóricas de competência e competência em informação, com a adoção de abordagem de tratamento e análise dos dados de cunho qualitativo, e utilização da técnica de análise de conteúdo, tendo como principal referencial metodológico o livro "Objetivo Competência: por uma nova lógica" de autoria de Philippe Zarifian (2001). 
A pesquisa qualitativa, segundo Demo (2011) faz jus à realidade, curvando-se diante dela busca o aprofundamento por familiaridade, convivência e comunicação, tentando preservar a dinâmica enquanto analisa, formalizando-a mais flexivelmente. Rampazzo (2013) refina o conceito da abordagem qualitativa definindo-a como uma compreensão particular daquilo que se estuda, almejando a absorção dos fenômenos estudados.

Nessa condição, interessou-nos realizar a análise de conteúdo da obra mencionada, a partir da releitura e compreensão das dimensões da competência em informação identificadas no discurso do autor.

Segundo Moraes (1999, p. 7) a análise de conteúdo, como técnica de avaliação metodológica, constitui

[...] uma metodologia de pesquisa usada para descrever e interpretar o conteúdo de toda classe de documentos e textos. Essa análise, conduzindo a descrições sistemáticas, qualitativas ou quantitativas, ajuda a reinterpretar as mensagens e a atingir uma compreensão de seus significados num nível que vai além de uma leitura comum (MORAES, 1999).

A análise de conteúdo representa um método utilizado para análise de dados qualitativos e compreende um conjunto de técnicas de pesquisa cujo objetivo alcança a descrição do conteúdo e busca de sentido em artigos e comunicações, largamente utilizado em pesquisas científicas (CAMPOS, 2004).A compilação das dimensões: técnica, estética, ética e política, identificadas na obra "Objetivo Competência: por uma nova lógica" de Philippe Zarifian (2001) buscaram nortear, portanto, o contexto da época em que se inserem as mudanças no modelo de competência e os elementos observados que remetem aos estudos atuais sobre a temática.

\section{Competência em informação: uma abordagem histórico-conceitual a partir de Zarifian}

A base conceitual para o desenvolvimento de estudos sobre o tema competência em informação surge no cerne do desenvolvimento dos modelos de produção, numa sociedade marcada pelo progresso tecnológico e científico em que informação e conhecimento tornam-se cada vez mais recursos estratégicos no mundo do trabalho e sociedade da informação.

A emergência da temática, segundo Miranda (2004, p. 2) se deu em 1970, "quando a palavra competência ainda estava ausente do vocabulário da época, com o surgimento das primeiras noções fundamentais que marcaram uma inversão de valores no modelo de trabalho vigente: autonomia, expressão individual e responsabilidade". 
Compreender a trajetória histórica das mudanças do contexto do trabalho tende a favorecer a relevância de se estudar trabalho/profissão e competência, no que concerne à transposição da noção da qualificação para o posto de trabalho a abordagens a respeito da "competência em informação".

O marco conceitual sobre o termo foi creditado em 1974, pelo americano Paul Zurkowski. A temática, cunhada sob a expressão InformationLiteracy, voltava-se na ocasião, ao desenvolvimento de habilidades, ao treinamento de profissionais para o uso da informação e ao aprendizado de técnicas para tratar dos aspectos informacionais, relacionados, sobretudo ao ambiente de trabalho (HATSCHBACH, 2002). Naquele cenário e, segundo a tradução literal para o português do Brasil, tratava-se do "letramento em informação", expressão que ainda é adotada por autores no cenário brasileiro, principalmente no que concerne ao âmbito escolar. Em virtude da utilização do termo no cenário do mundo do trabalho e de se referir, deste modo a pessoas em fase adulta, há um uso recorrente da expressão "competência em informação", adotada por Vitorino (2016) e disseminado sob esta perspectiva por inúmeros autores.

Assim, com o reconhecimento da relevância da informação e da competência em meio à formação e trabalho profissional, na década de 80, disseminou-se um movimento mundial para formar pessoas com habilidades de informação (MELO; ARAúJO, 2007). Nesta lógica, com a noção de informação como um atributo requerido pelas situações de trabalho, a qual supõe o conhecimento como matéria-prima para a operacionalização das tarefas, é possível mencionar o termo competência em informação, desenvolvido sob o contexto laboral.

Zarifian (2001), em sua obra "Objetivo Competência: por uma nova lógica", aponta a retrospectiva histórica acerca da emergência do modelo de competência em meados dos anos 80 , quando a temática começou a desenvolver-se nas empresas. A mudança do conceito de qualificação e as transformações das relações sociais, especialmente a evolução do trabalho, direcionaram a ideia de avaliar a competência dos funcionários independente do posto de trabalho.

Considerava-se em cenário anterior, habilidades corporais, como a destreza física e a rapidez na execução das tarefas. Com o questionamento do modo de avaliar os funcionários, surge a noção "do corpo ao cérebro", abandonando essa abordagem categorizada e formalizada da mão-de-obra e passando a avaliar o entendimento de problemas de desempenho e a capacidade de iniciativa dos funcionários sobre determinada tarefa no posto de trabalho (ZARIFIAN, 2001).

Um movimento da competência surgia como exigência da necessidade de aumentar a capacidade dos profissionais no entendimento e resolução de problemas circunstanciais, transformando as ações em 
resultados produtivos para a organização. O novo modelo concernia a novas práticas de gestão de pessoas. A emergência da educação continuada deriva do auge dessas novas práticas, quando se começou a acentuar a exigência de diploma como garantia de instrução de conhecimento, comportamento pessoal, responsabilização, compromisso e envolvimento com a empresa, em relação à melhoria contínua dos processos, o que permitia refinar a competência efetiva de cada indivíduo em relação às expectativas das empresas (ZARIFIAN, 2001).

A lógica da competência reafirma o conceito estreito da qualificação vinculada ao posto de trabalho. O abandono dessa noção estreita e a adoção do termo "competência em informação" enriquecem a temática, agregando-se, além da capacidade de mobilizar conhecimentos e saberes, também atitudes desenvolvidas pelas pessoas, aplicáveis ao posto de trabalho para a realização de atividades.

A relevância do termo competência para Zarifian (2001) surge junto às noções de eventos, comunicação e serviço, apresentadas em sua obra como mutações atuais no contexto do trabalho. Em meio a essas noções, o autor identifica dois aspectos inerentemente conectados:

a) "a competência deve, diante de um evento, ser automobilizada pelo indivíduo que se encontra na situação real, em seguida deve ser reconsiderada em uma análise a posteriori do evento" (ZARIFIAN, 2001, p. 43).

b) "o trabalho torna-se o prolongador direto da competência pessoal que um indivíduo mobiliza diante de uma situação profissional (diante de uma pane, diante de um problema apresentado por um cliente, diante do sucesso de uma inovação)" (ZARIFIAN, 2001, p. 57).

Ora, se como quer Zarifian (2001), a competência demonstra a capacidade de mobilizar diante de situações eventuais um entrecruzamento de ideias de implicação pessoal e coletiva, sobretudo no ambiente de trabalho, sem antecipar uma definição precisa de competência, fica claro que esta se liga à capacidade do profissional em lidar com eventos imprevisíveis, de se comunicar diante de determinado problema e de entender a natureza dos serviços, transformando estes eventos em conhecimento à medida que a diversidade de circunstâncias aumenta.

Podemos extrair deste contraponto que ser competente em informação, portanto, não se limita à habilidade de reconhecer quando a informação é necessária, localizar, avaliar e usar a informação de maneira efetiva na solução de problemas, como aponta a definição da ALA (1989), mas também, implicaria na capacidade da pessoa assumir iniciativa, ir além da mobilização da solução de um problema e entender/dominar 
novas situações no âmbito social e construtivo de aprendizagem contínua, em prol dos eventos que despontam no universo informacional.

Para Rios (2010) a competência não é algo estático, mas sim, desenvolvida cotidianamente no sentido de que vamos nos tornando competentes, a medida que amplia-se a construção da própria ação da pessoa por meio da abstração constante de conhecimentos, em referência a uma formação continuada.

É possível levar adiante que eventos, comunicação e serviço, mencionados por Zarifian (2001) necessitam estar presentes no conceito de competência, ao refletirmos que à medida que há envolvimento pessoal e coletivo no domínio de situações eventuais, vamos desenvolvendo a competência em informação em âmbito coletivo/social com uma aprendizagem contínua em torno de eventos que ocorrem cotidianamente. Ou seja, a mobilização pessoal em face de um evento compreende a capacidade de perceber e antecipar-se à determinada situação, a capacidade de compreender o "outro" no processo de comunicação, e, a capacidade de criatividade e reflexão pertinente à resolução e compreensão de um evento, considerando a partilha de experiências e a construção coletiva da competência com a absorção e transformação do nosso estado inicial de conhecimento. É possível, pois, desenvolver a competência em informação nesse sentido sob diversas faces.

Na visão de Rios (2010, p.91), a noção de competência "se amplia na construção coletiva" e inseparável da ação, como uma totalidade (VITORINO, 2009), alcança a essência de um saber fazer bem o dever, isto é, um fazer que requeira um conjunto de saberes, implicando que é preciso saber "bem" e saber fazer "bem" - um conjunto de experiências e saberes - revelados na articulação entre uma dimensão técnica, uma dimensão política e uma dimensão estética, mediadas pela ética. Estas dimensões serão situadas nas seções seguintes, mostrando a relação e o equilíbrio necessário existente entre elas, a fim de contextualizá-las na obra de Zarifian (2001).

\subsection{Dimensões da competência em informação}

No decorrer do espaço e do tempo, o ser humano será capaz de desenvolver um conjunto de capacidades, habilidades, saberes e conhecimentos no sentido de posicionar-se cognitivamente em relação à sociedade da informação. Esses elementos, representados como "um conjunto de", estão presentes na caracterização das dimensões da Competência em Informação e para que ela possa ser desenvolvida em plenitude, necessita ser norteada por quatro dimensões, em sintonia. (VITORINO; PIANTOLA, 2011). 
Apreciadas em Rios (2006), as dimensões: técnica, estética, ética e política, conforme Vitorino e Piantola (2011) contemplam as faces da competência em informação e em equilíbrio permeiam o seu desenvolvimento no âmbito individual, da coletividade e das relações sociais.

A dimensão técnica, na concepção de Rios (2010, p. 94) encontra-se vinculada àexecução da ação, é a realização ou forma específica do fazer. Pode ser entendida como um conjunto de saberes, habilidades e conhecimentos para o manuseio ou execução de uma ação em meio à intervenção prática da realidade (VITORINO, 2016). Refere-se ao saberfazer da competência em informação.

Segundo Vitorino e Piantola (2011) a ênfase sobre a técnica explica se por constituir a dimensão mais evidente da competência em informação, na medida em que representa a ação da pessoa no contexto da informação. Porém, quando desvinculada das outras dimensões como lembra Rios (2010, p. 94), seu significado torna-se empobrecido, por supervalorizar a técnica ignorando sua inserção no contexto político e social. Assim, a dimensão técnica, torna-se a base da competência em informação, mas só torna-se completa quando vinculada à ética, à política e à estética, que consolidadas e em equilíbrio permitem a construção da realidade social (VITORINO; PIANTOLA, 2011).

A dimensão estética como componente da competência relaciona-se à transformação dos saberes que serão compartilhados para o bem coletivo e reconstrução social. Pode ser entendida como a capacidade de inovar, criar e reerguer-se diante de uma situação. Na concepção de Rios (2010, p. 96), a dimensão estética é a "percepção sensível da realidade". Ou seja, diz respeito à presença da beleza, criatividade, inovação, mudanças e percepções pessoais orientadas à atividade em âmbito coletivo e a convivência social.

Conforme Vitorino e Piantola (2011, p.103) "a estética liga-se diretamente com a ética na busca da harmonia e da boa convivência em sociedade e no contexto coletivo" e igualmente, é associada à técnica. Agrega-se à dimensão ética, no que concerne à transformação das pessoas e da natureza por meio da reflexão interior e aprimoramento contínuo do trabalho para o bem coletivo. Articulando-se desse modo, com as demais dimensões.

A dimensão ética está relacionada à noção de autonomia, na medida em que a pessoa ética decide por si e por meio da crítica e pondera suas ações em prol da coletividade (VITORINO; PIANTOLA, 2011). Esta dimensão está condicionada à ideia de reflexão no contexto social, em que, segundo Vitorino e Piantola (2011, p.105) a pessoa competente em informação é aquela "[...] capaz de tomar posição, assumir uma postura crítica diante de determinadas informações" visando à realização do bem 
comum. A ética por guiar-se de comportamentos, responsabilidade, valores e atitudes torna-se a "dimensão fundante", e, constitui-se na base para as demais dimensões, pois segundo Rios (2010, p. 108) essas, só "ganharão seu significado pleno quando, além de se apoiarem em fundamentos próprios de sua natureza, se guiarem por princípios éticos".

Em relação à dimensão política, e, conforme Vitorino (2016, p. 394), "diz respeito ao compromisso político, ou seja, à participação na construção coletiva da sociedade e ao exercício dos direitos e deveres". Indica a visão crítica para o alcance das ações e o compromisso social. Ou seja, a política como uma dimensão da competência em informação considera a participação das pessoas nas transformações sociais e pode ser entendida como o trabalhar no sentido de alcançar uma meta transformar-se no sentido coletivo - se preocupar com o outro e com a necessidade da informação a partir de um contexto político.

O equilíbrio entre essas quatro dimensões, vistas em harmonia e sintonia entre o individual e o coletivo, torna-se condição essencial para que se estabeleça o desenvolvimento da competência em informação nas pessoas (VITORINO, 2016).

\section{As dimensões sob a perspectiva de Zarifian}

Em relação às dimensões da competência em informação apresentadas, recorremos à análise de conteúdo da obra "Objetivo Competência: por uma nova lógica" de autoria de PhillipeZarifian (2001), com o objetivo de analisar o discurso proferido pelo autor na década de 90, na perspectiva de identificar essas quatro dimensões no contexto da época.

Quanto à percepção da dimensão técnica na concepção do autor decorre da emergência do modelo da competência, sob o aspecto da valorização pessoal em relação ao "saber-fazer" operacional. O avanço do enfoque técnico da competência manifesta-se na obra em função da avaliação das ações e domínio técnico do trabalhador sobre o posto de trabalho. A técnica nesse sentido torna-se a base para a competência, pois é inerente ao entendimento prático das atividades (VITORINO, 2016).

Zarifian (2001, p.72) aponta para um conceito que revela a competência manifesta na ação. Segundo o autor, "a competência é um entendimento prático de situações que se apoia em conhecimentos adquiridos e os transforma na medida em que aumenta a diversidade das situações" (ZARIFIAN, 2001, p.72). Essa abordagem enfatiza a dimensão técnica da competência em informação, no que concerne à mobilização de entendimentos prévios em função de determinada situação remetendo a uma dimensão cognitiva associada a uma dimensão compreensiva. 0 quadro 1 sintetiza os elementos e trechos do texto do autor identificados na obra e que se referem à dimensão técnica. 
Quadro 1 - Dimensão técnica sob a perspectiva de Zarifian (2001).

\begin{tabular}{|c|c|}
\hline Dimensão & Concepções de Zarifian (2001) \\
\hline \multirow{7}{*}{$\begin{array}{c}\text { Técnica } \\
\text { (execução da ação - suporte da } \\
\text { competência em informação) }\end{array}$} & $\begin{array}{l}\text { "Nunca se é competente no abstrato. } \\
\text { Sempre se é competente "em relação à" } \\
\text { (ZARIFIAN, 2001, p.28). }\end{array}$ \\
\hline & $\begin{array}{l}\text { "Encontrar-se-á sempre uma descrição } \\
\text { inevitável do conteúdo técnico da } \\
\text { atividade" (ZARIFIAN, 2001, p.31). }\end{array}$ \\
\hline & $\begin{array}{l}\text { "A competência só se revela nas ações" } \\
\text { (ZARIFIAN, } 2001 \text { p.67). }\end{array}$ \\
\hline & $\begin{array}{l}\text { "A competência só se manifesta na } \\
\text { atividade prática" (ZARIFIAN, 2001, } \\
\text { p.67). }\end{array}$ \\
\hline & $\begin{array}{lll} & \text { "Dimensão puramente cognitiva" } \\
\text { (ZARIFIAN, 2001, p.72). } & \\
\end{array}$ \\
\hline & $\begin{array}{l}\text { Saber-fazer (ZARIFIAN, 2001, p.66; } \\
\text { p.120). }\end{array}$ \\
\hline & $\begin{array}{l}\text { Domínio técnico de novas ferramentas } \\
\text { (ZARIFIAN, 2001, p.120-121; p.135). }\end{array}$ \\
\hline
\end{tabular}

Fonte: Dados obtidos na pesquisa, 2018.

Evidencia-se, a partir dos elementos apresentados no Quadro 1, que a dimensão técnica está caracterizada em um "conhecimento para fazer" e associa-se à interpretação de comportamentos à luz da compreensão de determinada situação.

Desse conceito podemos extrair ainda, uma dimensão política, quando há a necessidade de interação social no entendimento de determinada situação, assim como uma dimensão ética associada à base da técnica, no tocante à maneira reflexiva com que necessitam ser mobilizados o conhecimento e a ação. Percebeu-se também, uma transposição da técnica para a estética, quando o autor reconhece a transformação e desenvolvimento de novos conhecimentos em prol das circunstâncias. $O$ aprender com a diversidade de situações no ambiente de trabalho, denota o caráter estético.

Torna-se perceptível que a competência deriva das ações desenvolvidas no contexto do trabalho. Uma análise mais detalhada, contudo, revela que essas ações, ou o domínio técnico de ferramentas, não são suficientes quando se trata da temática competência em informação. Segundo Zarifian (2001) a técnica em estado puro, tem relevância profissional cada vez menos significativa: a técnica pura segue importante em nível de conhecimentos, mas menos importante quando se trata da competência. 
Como podemos identificar na obra, a dimensão técnica da competência em informação não se manifesta unicamente, ocorre por meio do equilíbrio das dimensões ética e política, tendo a estética como elemento unificador de transformação social. Sob este ol har, o Quadro 2 resume a dimensão estética segundo a obra de Zarifian (2001).

Quadro 2 - Dimensão Estética sob a perspectiva de Zarifian (2001).

\begin{tabular}{|c|c|}
\hline Dimensão & Concepções de Zarifian (2001) \\
\hline \multirow{11}{*}{$\begin{array}{c}\text { Estética } \\
\text { (transformação, reconstrução, percepção } \\
\text { sensível da ação) }\end{array}$} & $\begin{array}{l}\text { Capacidade de antecipação; expectação } \\
\text { atenta antes da ocorrência de um evento } \\
\text { (atitude; iniciativa) (ZARIFIAN, 2001, } \\
\text { p.41). }\end{array}$ \\
\hline & $\begin{array}{l}\text { Capacidade de intervenção ativa e } \\
\text { pertinente à resolução de uma situação } \\
\text { (criatividade) } \\
\text { (ZARIFIAN, 2001, p.41). }\end{array}$ \\
\hline & $\begin{array}{llr}\text { "Novos problemas colocados } & \text { pelo } \\
\text { ambiente mobilizam atividades } & \text { de } \\
\text { inovação" (ZARIFIAN, 2001, p.42) } \\
\text { (criatividade; inovação). }\end{array}$ \\
\hline & $\begin{array}{l}\text { Atividade sensível diante de uma situação } \\
\text { de evento. Decisões sensíveis. Papel } \\
\text { sensível (ZARIFIAN, 2001, p.42-43). }\end{array}$ \\
\hline & $\begin{array}{l}\text { "Para conduzir um projeto, o quinhão de } \\
\text { inovação e de criatividade é, em princípio } \\
\text { grande"; "Espírito de inovação" } \\
\text { (ZARIFIAN, 2001, p. 62). }\end{array}$ \\
\hline & $\begin{array}{l}\text { "Tomar iniciativa é uma ação que } \\
\text { modifica algo que existe, que introduz } \\
\text { algo novo, que começa alguma coisa, que } \\
\text { cria" (ZARIFIAN, 2001, p. 69). }\end{array}$ \\
\hline & $\begin{array}{l}\text { "Capacidades de imaginação e de } \\
\text { invenção que permitem abordar o singular } \\
\text { e o imprevisto" (ZARIFIAN, 2001, p. 69). }\end{array}$ \\
\hline & $\begin{array}{l}\text { "Transformação da profissionalidade" } \\
\text { (ZARIFIAN, 2001, p.85). }\end{array}$ \\
\hline & $\begin{array}{l}\text { "Potencial de criatividade e capacidade de } \\
\text { iniciativa" (ZARIFIAN, 2001, p.85). }\end{array}$ \\
\hline & $\begin{array}{l}\text { "Os assalariados são sensíveis ao futuro } \\
\text { da empresa" (ZARIFIAN, 2001, p.90). }\end{array}$ \\
\hline & $\begin{array}{l}\text { "Aprender a contestar a maneira de fazer } \\
\text { as coisas; recorrer a experimentações e } \\
\text { melhorias; transformação mútua entre } \\
\text { competência e desempenho"; "Não se } \\
\text { trata apenas de "ter" um desempenho. É }\end{array}$ \\
\hline
\end{tabular}




\begin{tabular}{|l|l|}
\hline & preciso melhorá- lo" (ZARIFIAN, 2001, \\
& p.94); “Criação de valor” (ZARIFIAN, \\
& 2001, p.137).
\end{tabular}

Fonte: Dados obtidos na pesquisa, 2018.

A dimensão estética revelada pela perspectiva criadora e inovadora sob o saber e fazer profissional direciona-se no contexto da obra, à capacidade de transformação e percepção sensível acerca dos problemas colocados pelo ambiente de trabalho e à emergência de novas necessidades.

Como podemos perceber no Quadro 2, a dimensão estética da competência identifica-se na obra pela mobilização do indivíduo no confronto de eventos ou situações imprevisíveis do contexto das organizações, na capacidade de antecipar-se à ocorrência de um evento, de unir criatividade, inovação e imaginação para a melhoria dos processos de desempenho e tomada de decisão.

Salienta Vitorino (2016, p. 394) que a estética "ligada à ordenação de sensações, à apreensão consciente da realidade, à intelectualidade e à afetividade dos indivíduos orienta-se para a atividade social, significativa para o bem social e coletivo".

A dimensão estética da competência em informação, nesse sentido, relaciona-se à construção de novos conhecimentos, por meio da sensibilidade, criatividade, espírito de inovação e transformação ética e social identificadas nas concepções de Zarifian (2001).

Seguindo esta linha de raciocínio e no contexto mencionado por Zarifian (2001) a dimensão ética permeia toda a obra do autor, no tocante à orientação para a ação, fundada nos princípios de responsabilidade, análise crítica em relação aos eventos e situações de trabalho, comportamento diante de determinada situação assim como o assumir valores éticos profissionais em face do bem comum/ coletivo (Quadro 3).

Visa Zarifian (2001, p.141) que "desenvolver uma competência é também proceder, em suas relações com outros, com civilidade, ou seja, proceder com atenção, respeito e generosidade em face do outro."

Podemos perceber que a dimensão ética orientada por princípios para a boa conduta dos indivíduos nas ações e reflexões de eventos e situações imprevisíveis. A presença dos valores éticos profissionais destaca-se na obra, pela noção de responsabilidade, respeito e generosidade corroborando no âmbito da coletividade e das relações sociais, sobretudo no ambiente de trabalho.

Pensar criticamente, segundo Rios (2010), significa considerar possibilidades no intuito de aperfeiçoar diante de situações uma postura de questionamentos e reflexões que direcionam a ampliação de conhecimentos e ao processo de educação contínua. Este processo se 
torna pleno quando "ao lado da razão, a imaginação, os sentimentos e os sentidos" se refletem na ação do indivíduo (RIOS, 2010, p. 61)

Quadro 3 - Dimensão Éticasob a perspectiva de Zarifian (2001).

\begin{tabular}{|c|c|}
\hline Dimensão & Concepções de Zarifian (2001) \\
\hline \multirow{10}{*}{$\begin{array}{c}\text { Ética } \\
\text { (comportamentos, valores, atitudes, } \\
\text { reflexão crítica no âmbito coletivo e } \\
\text { social) }\end{array}$} & $\begin{array}{l}\text { Capacidade de reflexão após um evento, } \\
\text { para compreensão das causas e motivos } \\
\text { para que o mesmo não volte a ocorrer } \\
\text { (reflexão crítica) (ZARIFIAN, p.41-44). }\end{array}$ \\
\hline & $\begin{array}{l}\text { "Análise crítica e sistemática dos eventos } \\
\text { (suas causas, sucessos, fracassos, } \\
\text { tentativas para dominá-los" (ZARIFIAN, } \\
\text { 201, p.44). }\end{array}$ \\
\hline & $\begin{array}{l}\text { "Assumir uma situação de trabalho e ser } \\
\text { responsável por ela"; "responsabilidade a } \\
\text { um agente" (ZARIFIAN, 2001, p. 68). }\end{array}$ \\
\hline & $\begin{array}{l}\text { "O indivíduo enquanto sujeito de suas } \\
\text { ações" (ZARIF IAN, 2001, p.68). }\end{array}$ \\
\hline & $\begin{array}{lcc}\text { "Disposição } & \text { para } & \text { assumir } \\
\text { responsabilidade } & \text { pela } & \text { situação" } \\
\text { (ZARIFIAN, 2001, p.70). } & \end{array}$ \\
\hline & $\begin{array}{l}\text { "responder por, é também, assumir } \\
\text { valores" (ZARIFIAN, 2001, p.70). }\end{array}$ \\
\hline & $\begin{array}{l}\text { "comportamento possível do sujeito } \\
\text { diante de uma situação" } \\
\text { 2001, p.42). }\end{array}$ \\
\hline & $\begin{array}{l}\text { Situações mais complexas excedem a } \\
\text { competência individual e se baseiam na } \\
\text { solidariedade da ação, na competência } \\
\text { coletiva corroborando eticamente na } \\
\text { tomada de iniciativa (ZARIFIAN, p.115- } \\
\text { 116). }\end{array}$ \\
\hline & $\begin{array}{l}\text { Hábito reflexivo em relação ao coletivo; } \\
\text { Hábito de questionar as situações } \\
\text { profissionais (ZARIFIAN, p.115-117). }\end{array}$ \\
\hline & $\begin{array}{l}\text { "Ser bom; tomar boas decisões e apoiar-se } \\
\text { em regras gerais; direito de julgar } \\
\text { situações" (ZARIFIAN, 2001, p.93). } \\
\text { "Consciência profissional." "valores } \\
\text { éticos profissionais." (atenção, respeito, } \\
\text { generosidade em face do outro) } \\
\text { (ZARIFIAN, 2001, p.123-125) }\end{array}$ \\
\hline
\end{tabular}

Fonte: Dados obtidos na pesquisa, 2018. 
Ao nortear a ação, os valores e hábitos reflexivos diante do coletivo no processo de trabalho, a dimensão ética constitui base que sustenta as demais dimensões identificadas e mediadas pela mesma.

É no coletivo que a contribuição da dimensão política revela-sena obra de Zarifian (2001). Esta remete ao discurso do autor nas relações inter-humanas e sociais, enfatizando a abordagem social manifesta pela autonomia, responsabilidade e atitudes sociais, mediante interações e comprometimentos em relação ao coletivo. O Quadro 4 apresenta a dimensão política explícita no texto do autor.

Quadro 4 - Dimensão Política sob a perspectiva de Zarifian (2001).

\begin{tabular}{|c|c|}
\hline Dimensão & Concepções de Zarifian (2001) \\
\hline \multirow{7}{*}{$\begin{array}{c}\text { Política } \\
\text { (transformação no sentido coletivo, } \\
\text { preocupação com o outro) }\end{array}$} & $\begin{array}{l}\text { "A responsabilidade é particularmente } \\
\text { importante na medida em que toca outros } \\
\text { humanos"(ZARIFIAN, 2001, p.70). }\end{array}$ \\
\hline & $\begin{array}{l}\text { "O entendimento das razões do outro } \\
\text { permite compreender "inteligentemente" } \\
\text { seu próprio comportamento." (interação } \\
\text { social) (ZARIFIAN, 2001, p.72). }\end{array}$ \\
\hline & $\begin{array}{l}\text { Compartilhar as implicações de uma } \\
\text { situação possibilita um sentido coletivo às } \\
\text { açôes(ZARIFIAN, 2001, p.74-75). }\end{array}$ \\
\hline & $\begin{array}{l}\text { Capacidade de "agir localmente, tendo a } \\
\text { preocupação e a visão dos efeitos globais" } \\
\text { (ZARIFIAN, 2001, p.92). }\end{array}$ \\
\hline & $\begin{array}{l}\text { Responsabilidade coletiva; gestão das } \\
\text { interações com outros } \\
\text { (ZARIFIAN, 2001, p.119) }\end{array}$ \\
\hline & $\begin{array}{l}\text { "Relações inter-humanas" (relações } \\
\text { sociais) (ZARIFIAN, 2001, p.119; p.143). }\end{array}$ \\
\hline & $\begin{array}{lcc}\text { Competência } & \text { social }- & \text { saber-ser } \\
\text { (ZARIFIAN, 2001, p.146-149) } & \\
\end{array}$ \\
\hline
\end{tabular}

Fonte: Dados obtidos na pesquisa, 2018.

Mediante confronto entre o individual e o coletivo que a dimensão políticase estabelece, ao surgimento da competência coletiva em equipe de trabalho representada como maior do que a soma das competências individuais (ZARIFIAN, 2001, p. 116).

A competência segundo Zarifian (2001, p. 63) "é assumida no coletivo, mas depende de cada pessoa individualmente". A competência em informação sob essa ótica se apresenta no outro, ou seja, é pelo 
outro, no sentido da coletividade, que podemos perceber a sua manifestação, a qual só faz sentido no âmbito coletivo e social. Compreende o homem enquanto ser social (VITORINO; PIANTOLA, 2011). Sob a perspectiva de avaliar os funcionários por suas qualidades e características pessoais, nasce o saber-ser em relação ao comportamento social, relacionado à contribuição desses elementos individuais nas interações humanas do trabalho.

Salienta Vitorino, (2009, p. 56) que ao tratarmos da noção de competência torna-se oportuno trabalhar com a perspectiva coletiva, no tocante à partilha de experiências e reflexão, à medida que o individual se amplia na construção coletiva. Assim, a dimensão política liga-se à ética e à estética em relação ao seu caráter de reflexão e transformação no sentido coletivo, e, à técnica pela demanda de ações inseridas no âmbito político e social.

\section{Aspectos conclusivos}

A proposta deste artigo consistiu em analisar a obra "Objetivo Competência: por uma nova lógica" de PhillipeZarifian (2001) a fim de identificar as quatro dimensões, técnica, estética, ética e política da competência, no contexto da década de 90 e a partir de releitura e análise de conteúdo dos capítulos, conduzir a reflexões acerca da temática.

Conforme apresentadas nos quadros 1, 2, 3 e 4, as concepções de Zarifian (2001) expõem o desenvolvimento do modelo de competência nas dimensões técnica, estética, ética e política com ênfase na transição da lógica do trabalho à lógica da competência, no contexto da década de 90, as quais se complementam e se equilibram em face das mudanças.

Evidenciam-se as dimensões anunciadas por Rios (2006; 2010) e teorizadas por Vitorino e Piantola (2011) para a Ciência da Informação presentes implicitamente no discurso proferido pelo autor na época de transição da noção de qualificação para o modelo de competência, o que denota uma conexão de ideias e reflexão das dimensões apresentadas nas diferentes perspectivas e contextos: no trabalho (ZARIFIAN, 2001), na educação (RIOS, 2006) e na Ciência da Informação (VITORINO; PIANTOLA, 2011).

A dimensão técnica revelada nas ações, no saber-fazer e no "ser competente em relação à"; a estética com a proporção de criatividade, sensibilidade, espírito de inovação e imaginação e as dimensões ética e política presentes na responsabilidade, valores e interação coletiva, desenvolvidas em equilíbrio, como expostas na obra, proporcionam o desenvolvimento de um profissional que busca em suas ações o bem estar coletivo e favorecem o agir significativamente em construção da realidade e o desenvolvimento da competência em informação na contemporaneidade. 
Outro aspecto a considerar, igualmente relevante: as dimensões se "cruzam", na medida em que estas dependem umas das outras, ou seja, não há linearidade ou dimensão que se apresente sozinha. Cada dimensão apresenta elementos característicos de outras dimensões que a complementa. Por exemplo, quando na dimensão técnica se percebe elementos da dimensão política, que se apresenta na necessidade de interação social e na compreensão de determinada situação para que a ação se efetive. Ou, quando a dimensão ética está associada à base da técnica, no tocante à maneira reflexiva necessária à ação. E ainda, quando a estética, necessária à transformação e desenvolvimento de novos conhecimentos, demonstra-se nas situações e no ambiente de trabalho.

A lógica da competência corrobora com o abandono da noção da qualificação para o posto de trabalho e adoção do termo "competência em informação", conforme seu desenvolvimento nas pessoas. Há deste modo, na dimensão política, o saber-ser em relação ao comportamento social, relacionado à contribuição dos elementos individuais nas interações humanas do trabalho.

Entre a lógica da competência, inicialmente construída pelo autor francês Zarifian (2001), e a competência em informação, diluem-se a essência da noção originária do termo, no tocante ao desenvolvimento de habilidades e treinamento profissional voltados ao aprendizado contínuo para atuação no ambiente de trabalho. Cenário que vai se modificando conforme surgem mutações em contexto social.

A busca por reflexões sobre as dimensões elucidadas na obra de Zarifian (2001), em contexto da época apresentada, ganha relevância na promoção e desenvolvimento da competência em informação em contexto laboral, como elemento capaz de tornar inovação, criatividade, domínio técnico, reflexão ética e interação coletiva, orientados ao desenvolvimento de conhecimento contínuo, como ações conduzidas à antecipação de circunstâncias e situações que podem ocorrer no ambiente de trabalho.

As contribuições das dimensões técnica, estética, ética e política, elucidadas no discurso do autor, tornam-se oportunas nos estudos acerca da temática na Ciência da Informação, na Biblioteconomia e na Arquivologia, inclusive, ao demonstrar que a competência em informação desenvolvida no ser humano, favorece o conhecimento, a autonomia e a criatividade com espírito crítico e inovador em prol da coletividade e em meio ao contexto laboral.

\section{Referências}

ALMEIDA, Mario de Souza. Elaboração de projeto, TCC, dissertação e tese:uma abordagem simples, prática e objetiva. São Paulo: Atlas, 2011. $80 \mathrm{p}$. 
AMERICAN LIBRARY ASSOCIATION (ALA).Association of College and Research Libraries (ACRL).Presidential Committee on Information Literacy: Final Report (January 1989). Disponívelem: http://libguides.ala.org/InformationEvaluation/Infolit. Acesso em: 29 abr. 2020.

BARROS, Aidil Jesus da Silveira; LEHFELD, Neide Aparecida de Souza. Fundamentos de metodologia científica. 3 ed. São Paulo: Pearson, 2007.

CAMPOS, Claudinei José Gomes. Método de análise de conteúdo: ferramenta para a análise de dados qualitativos no campo da saúde. Revista Brasileira Enfermagem, Brasília (DF), v. 57, n. 5, p.611-4, set./out. 2004. Disponível em: https://www.scielo.br/pdf/reben/v57n5/a19v57n5.pdf. Acesso em: 03 maio 2020.

DEMO, Pedro. Metodologia do conhecimento científico. São Paulo: Atlas, 2011.

FREIRE, Gustavo Henrique de Araújo. O trabalho de informação na sociedade do aprendizado contínuo. Informação \& Sociedade: Estudos, João Pessoa, v. 17, n.3, p.39-45, set./dez.2007. Disponível em: http://memoria.Iti.pro.br/userfiles/downloads/eticaDaInformacao/Modulo7 106\%20Trabalho\%20com\%20informacao.pdf. Acesso em: 05 maio 2020.

HATSCHBACH, Maria Helena. InformationLiteracy: aspectos conceituais e iniciativas em ambiente digital para o estudante de nível superior. 2002. Dissertação (Mestrado em Ciência da Informação_ Pós-graduação em Ciência da Informação do MCT/IBICT - UFRJ/ECO, Universidade Federal do Rio de Janeiro, Rio de Janeiro, 2002. Disponível em: http://ridi.ibict.br/bitstream/123456789/722/1/mariahelena2002.pdf. Acesso em: 20 mar. 2018.

KERLINGER, Fred Nichols. Metodologia da pesquisa em ciências sociais: um tratamento conceitual. São Paulo: E.P.U., 2013.

MELO, Ana Virgínia Chaves de.; ARAÚJO, Eliany Alvarenga de. Competência informacional e gestão do conhecimento: uma relação necessária no contexto da sociedade da informação. Perspectivas em Ciência da Informação, Belo Horizonte, v. 12, n. 2, p. 185-201, maio/ago. 2007. Disponível em: http://www.scielo.br/pdf/pci/v12n2/v12n2a12.pdf. Acesso em: 16 mar. 2018.

MIRANDA, Silvânia Vieira. Identificando competências informacionais. Ciência da informação, Brasília, DF, v. 33, n. 2, p.112-122, maio./ago. 2004. Disponível em: http://revista.ibict.br/ciinf/article/view/1053/1131. Acesso em: 08 fev. 2018. 
MORAES, Roque. Análise de conteúdo. Revista Educação, Porto Alegre, v. 22, n.37, p.7-32, 1999. Disponível em:

http://cliente.argo.com.br/ mgos/analise de conteudo moraes.html. Acesso em: 03 maio 2020.

RAMPAZZO, Lino. Metodologia científica: para alunos dos cursos de graduação e pós-graduação. 7 ed. Edições Loyola, 2013.

RIFKIN, Jeremy. A terceira revolução industrial: como o poder lateral está transformando a energia, a economia e o mundo. São Paulo, SP: M. Books do Brasil, 2012.

RIOS, Terezinha Azerêdo.Ética e competência. São Paulo: Cortez, 1993a.

RIOS, Terezinha Azerêdo. Ética e interdisciplinaridade. In: FAZENDA, Ivani. Apesquisa em educação e as transformações do conhecimento. Campinas: Papirus, 1995a.

RIOS, Terezinha Azerêdo. A dimensão ética da profissão. Hypnos,São Paulo, v.2, n.3, p.38-44, 1997.

RIOS, Terezinha Azerêdo. Projeto pedagógico: uma construção coletiva. In:SEMINÁRIOS DE ATUALIZAÇÃO PEDAGÓGICA.Bragança Paulista: UFSC, 1998.

RIOS, Terezinha Azerêdo. Ética e competência. 14. ed. São Paulo: Cortez, 2004 (Coleção Questões da Nossa Época, v. 16).

RIOS, Terezinha A. Compreender e ensinar: por uma docência de melhor qualidade. 6.ed. São Paulo: Cortez, 2006.

RIOS, Terezinha Azerêdo. Compreender e Ensinar: por uma docência de melhor qualidade. 8ed. São Paulo: Cortez, 2010.

TOMASI, Antônio (org.). Da qualificação à competência: pensando o século XXI. Campinas, São Paulo: Papirus, 2004.

VITORINO, Elizete Vieira. Competência Informacional do profissional da informação bibliotecário: construção social da realidade. Enc. Bibli:R. Eletr. Bibliotecon. Ci. Inf., Florianópolis, v. 12, n. 24, p. 59-71, 2. sem. 2007. Disponível em:

https://periodicos.ufsc.br/index.php/eb/article/view/1518-

2924.2007v12n24p59/410. Acesso em: 15 fev. 2018.

VITORINO, Elizete Vieira. Princípios epistemológicos à competência informacional do profissional da informação. In: CONGRESS ISKO-SPAIN, 
9., 11-13, mar., 2009. Disponível em: http://www.iskoiberico.org/wpcontent/uploads/2014/09/57-72 Vieira-Vitorino.pdf. Acesso em: 15 fev. 2018.

VITORINO, Elizete Vieira. Análise dimensional da Competência Informacional: bases teóricas e conceituais para reflexão. Revista IberoAmericana de Ciência da Informação, v. 9 n.2, p. 421-440, 2016.

Disponível em:

https://periodicos.unb.br/index.php/RICI/article/view/2420. Acesso em: 05 abr. 2020.

VITORINO, Elizete Vieira; PIANTOLA, Daniela. Competência Informacional - bases históricas e conceituais: construindo significados. Ciência da Informação, Brasília, DF, v. 38, n. 3, p. 130-141, set./dez. 2009. Disponível em: http://www.scielo.br/pdf/ci/v38n3/v38n3a09.pdf. Acesso em: 15. Fev. 2018.

VITORINO, Elizete Vieira; PIANTOLA, Daniela. Dimensões da competência informacional (2). Ciência da Informação, Brasília, DF, v.40, n.1, p.99110, jan./abr., 2011. Disponível em:

http://revista.ibict.br/ciinf/article/view/1328. Acesso em: 15fev. 2018.

VITORINO, Elizete Vieira; PIANTOLA, Daniela. Competência em informação: conceito, contexto histórico e olhares para a Ciência da Informação. Florianópolis: UFSC, 2019.

ZARIFIAN, Phillipe. Objetivo competência: por uma nova lógica. São Paulo (SP): Atlas, 2001.

ZURKOWSKI, P. G. The Information Service Environment Relationships and Priorities: report 5. Washington, D.C., National Commission on Libraries and Information Science, Nov 1974. Disponível em: http://files.eric.ed.gov/fulltext/ED100391.pdf. Acessoem: 27 abr. 2020. 